\title{
MEASURING STRAIN OF THE LATTICE TOWERS
}

The paper deals with strain measuring of bolted steel lattice high voltage tower structure on the test field. This measurement was associated to the test according to international standard IEC 60652, Ed. 2.0. If the tower is simulated as a truss structure and we expect the linear behavior of this object then the test data and calculation may show variations. The displacements of screw joint were detected as a source of this variation or non linear properties of structure. The key to this conclusion was detection of peak in measurement data.

Keywords: strain gauge, bolted lattice tower, non linearity, screw, peak detection

\section{Introduction}

The tests of the real objects are often expensive. The numerical models based on finite elements or meshless formulation play important role in estimating mechanical properties of these objects [1-4]. The models are necessary to verify the tests. In the case the test object is destroyed during test (according the test program) and the test is impossible to repeat with the same object then high demands are also placed on the preparation of test methods used, and related measurements.

This group includes the tests of bolted steel lattice high voltage tower structure, which are implemented in the company of our customer, according to specific customer requirements. The determination of deformation in selected parts of the tower was solved by the Faculty of Mechanical Engineering University of Zilina, Department of Applied Mechanics and Department of Design and Mechanical Elements. The paper deals with the preparation of measurement, its execution and interpretation of results. The interpretation will focus on possible sources of deviations between measured and calculated results.

\section{The Basic Assumptions and Preparation of the Test}

The subject test was bolted steel lattice high voltage tower structure made to the customer. The methodology for the test was prepared by customer according to international standard IEC 60652, Ed. 2.0. The tower was loaded by vertical and horizontal forces. First, there was a load force in the vertical direction to simulate the gravitational forces of ropes and ice, then there was a load tower in the horizontal direction, this simulates the effect of wind load acting perpendicular to the direction of power lines, Fig. 1. The strength in the horizontal direction was gradually step by step increased until the plastic deformation of the column correspond- ing to the collapse of the structure. In describing the test was a requirement of determining the strain (deformation) in the axial direction of the trusses, due to tensile - compressive forces in the members truss structures. It was just assuming the presence of axial forces only and it was necessary to make measurements at selected locations L-tower profiles on both parts of the L-profile. The customer intends to compare own computational model with the experiment.

As the measuring points were also located at height up to 20 meters of ground on the assembled column and measurement should be made at temperatures below $0{ }^{\circ} \mathrm{C}$, strain gauges and wires were installed on the chosen elements of the tower or the partially assembled parts of the tower in the production hall. The functionality of sensors was verified with wires and calibration was performed too. Checking and calibration was repeated after standing the tower on the test field, and also just prior to the test.

The strain gauges Micro-Measurement Division Vishay were used, namely CEA-06-250UW-120 and installation technology of Vishay too. The sensors were installed at the customers required locations. Some of the locations are shown in Fig. 1.

Four gauges were used in a full bridge connection, with two active gauges in the axial direction of member and two dummy gauges to eliminate temperature effects were placed transverse to the applied strain, Fig. 2.

The bridges were connected to the five cDAQ National Instruments 9237 modules ( 4 channel, 24-bit resolution, $50 \mathrm{kS} / \mathrm{s} /$ channel maximum sampling rate, cDAQ NI bridge module) in NI 9178 chassis, by using 8-wires cable. 8 wire connections allow to control the supply voltage to the bridge, eliminate the resistance of wires whose length was varied in the test and reached the $60 \mathrm{~m}$ and allows precision calibration of bridges [5]. This configuration was

\footnotetext{
* Vladimir Dekys, Jozef Broncek

Department of Applied Mechanics and Department of Design and Mechanical Elements, Faculty of Mechanical Engineering, University of Zilina,

Slovakia, E-mail: vladimir.dekys@fstroj.uniza.sk
} 


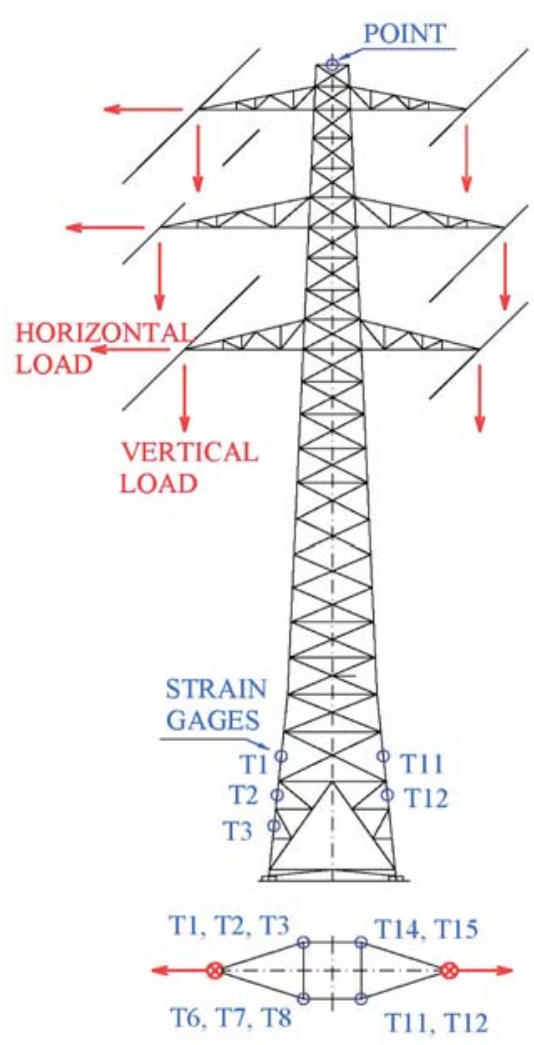

Fig. 1 Load of tower with chosen strain gauges places

also installed on the test element in the laboratory of the Faculty of Mechanical Engineering and the installation with the whole measuring string was verified on a test stand too. The properties installed sensors and the measuring system was also tested at ambient temperature below $-10^{\circ} \mathrm{C}$. It should be noted that the bridge does not eliminate the potential bending in members.
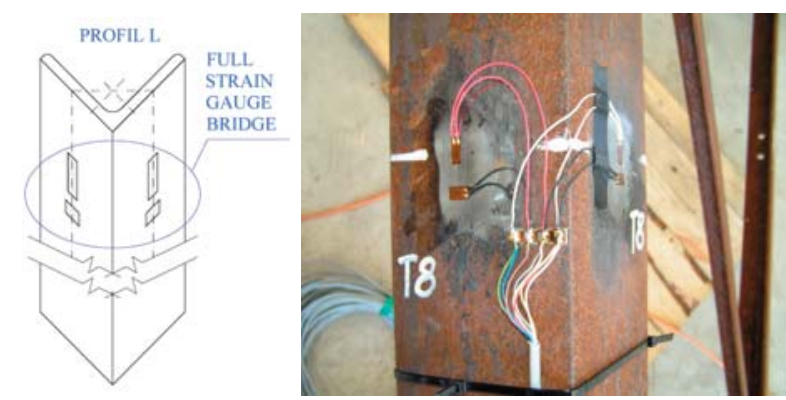

Fig. 2 A position of strain gauges on the chosen place of L-profile

The strain (deformation) $e_{\mu \varepsilon}[\mu \varepsilon]$ for different load stage is generally defined:

$$
e=\frac{\Delta L}{L}, 1 \mu \varepsilon=10^{-6}, e=10^{-6} e_{\mu \varepsilon}
$$

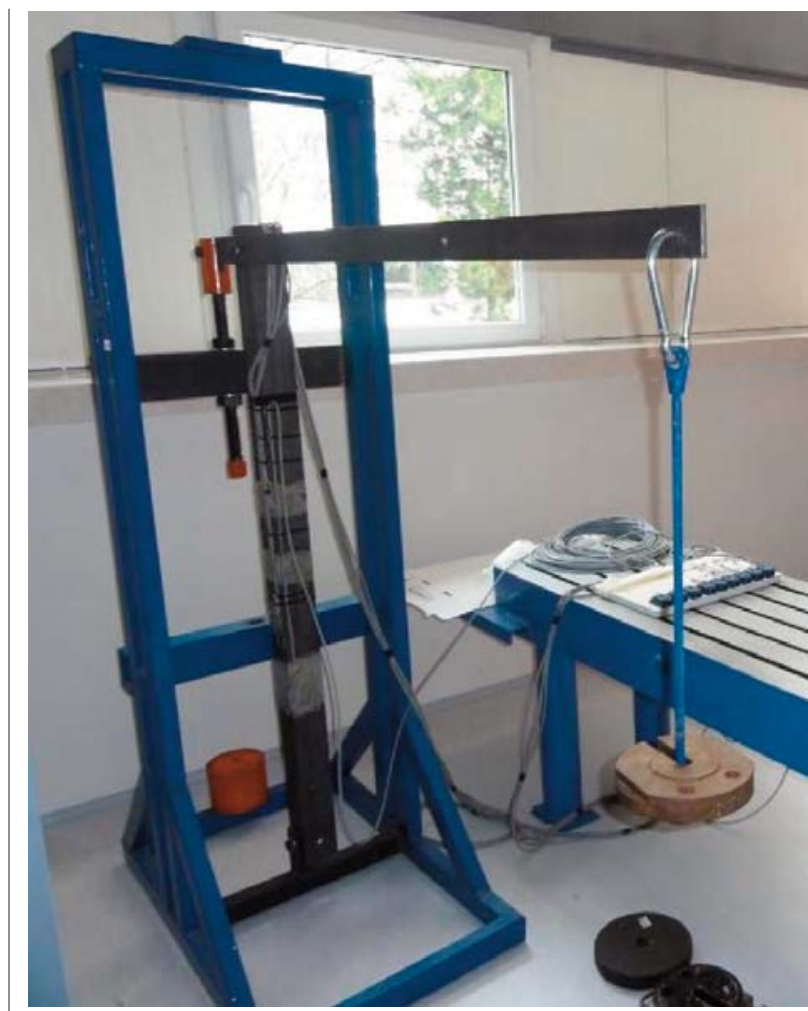

Fig. 3. The test stand to verify the installation of strain gauges and the whole measuring chain

$e$ [1] is the measured strain, [1],

$L[1]$ is the active grid length of strain gauge, [m]

$\Delta L[1]$ is the change of active grid length of strain gauge, [m].

For full-bridge type III, [6]:

$$
\begin{aligned}
& e=\frac{-2 V_{R}}{G F\left[(\nu+1)-V_{R}(\nu-1)\right]}, \\
& V_{R}=\frac{V_{C H}(\text { strained })-V_{C H}(\text { unstrained })}{V_{E X}}
\end{aligned}
$$

$V_{C H}$ is the measured signal's voltage, [V],

$V_{E X}$ is the excitation voltage, [V],

$v$ is the Poisson's ratio, defined as the negative ratio of transverse strain to the axial strain (longitudinal) strain, [1],

GF is gauge factor, [1].

The tensile - compressional force $F[\mathrm{kN}]$ :

$$
F=E A\left(10^{-6} e_{\mu \varepsilon}\right) / 1000,
$$

$E \quad$ is Young's modulus of elasticity, [N/mm],

$A$ is area of cross section, [mm].

The measured data are below the yield stress value, therefore the linear model is sufficient. In the case of the nonlinear region, 
we have to use the tensile curve. Based on the shape of the tensile curve then we would determine the bilinear or multilinear model according to which the Young's modulus E would be changed in the formula (3).

\section{Resutls}

The results of measurement are depicted in Figs. 4-6.

In Fig. 4 is depicted strain - deformation of chosen parts versus number of samples. It presented step by step increasing of strain (in absolute value) according to the increase of horizontal load Rapid decrease of compressive strain (divergence of curves) in bottom of Fig. 4 is important. If the top curves (tensile strain) presented linear increase of strain, then the bottom curves (compressive strain) presented non linear decrease.

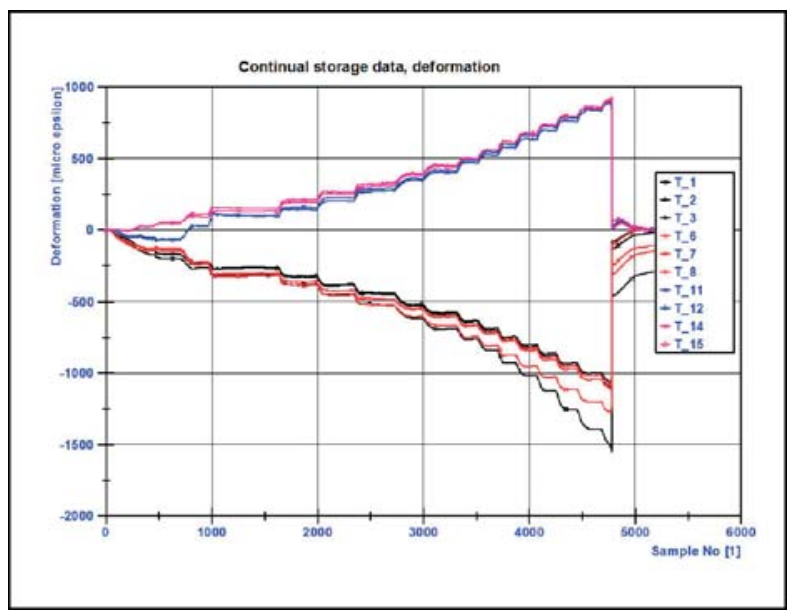

Fig. 4. An overall record of deformation (strain) in stepwise increasing of test load

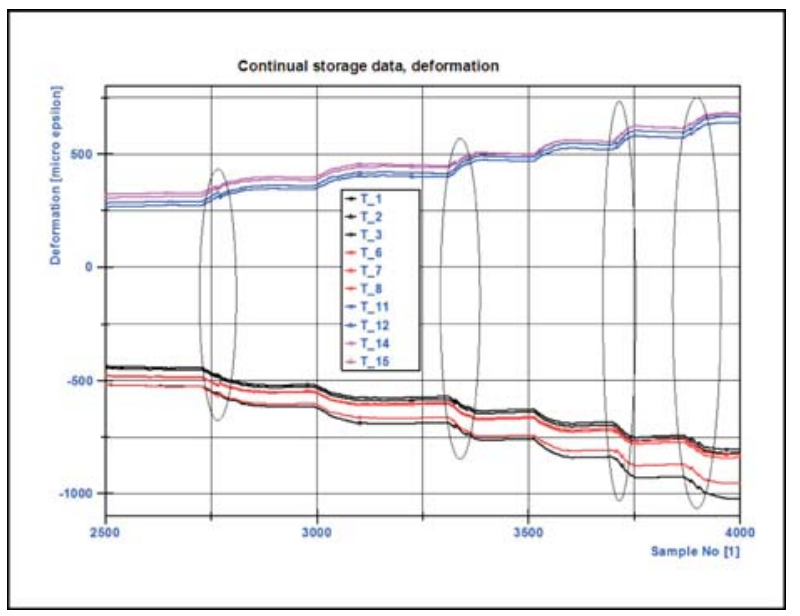

Fig. 5. Zoom of Fig. 4. Inside the ellipse are recognized peaks of strain
In Fig. 5 is depicted zoom of Fig. 4. Inside the ellipse are recognized peaks of strain. This phenomenon is explained as a displacement of parts of truss structure on the base tolerances in the holes of bolts.

In Fig. 6 is depicted zoom of Fig. 4 too. After this displacement are recognized next displacements in the bolt's holes, Fig. 4. This moment was recognized as a start of non linear properties of strain on the tested object.

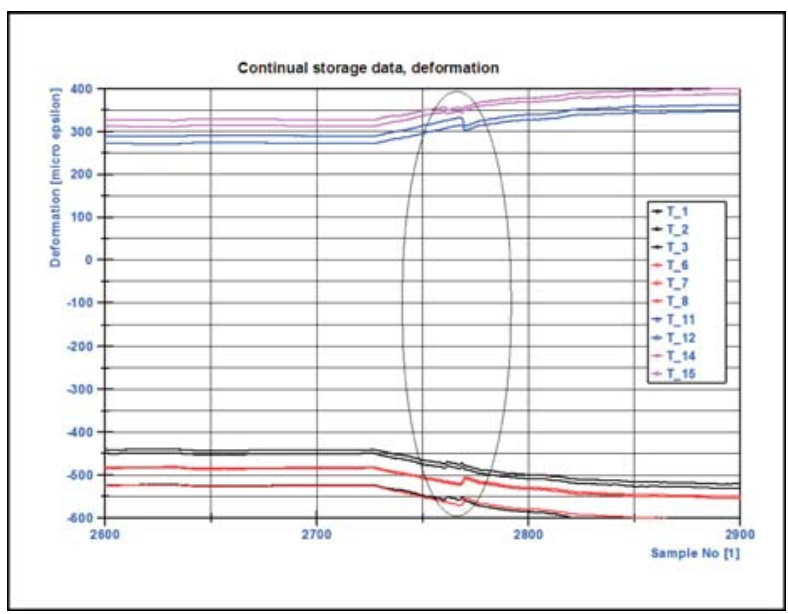

Fig. 6 Zoom of Fig. 4. Inside the ellipse are recognized peaks of strain

In Fig. 7 is depicted zoom of Fig. 4 for T 1 , average values and original data stored with sampling frequency of $1 \mathrm{kHz}$. The displacement is recognized, it is marked with ellipse.

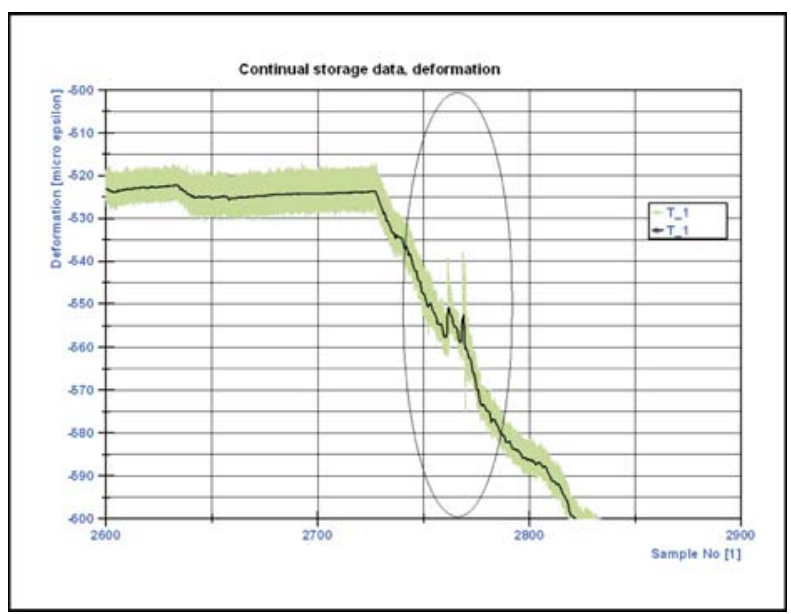

Fig. 7 Zoom of Fig. 4. Inside the ellipse are recognized peaks of strain, black - average data and grey - original stored data with sampling frequency of $1 \mathrm{kHz}$ 


\section{Conclusion}

The objective of the paper was to present the experiences with strain measurements of bolted steel lattice high voltage tower structure and interpret non linear properties of measured strain. The displacements of members truss structure in screw bolts is presented in measurement data as a start of this non linear relation. The displacement of elements can cause a violation of the construction and the location of loading forces can be changed too.
The peaks are presented in the strain measured data. These changes are not implemented in usual computers models. The plastic deformation of truss is not source the peaks identified in the measured data in this paper. The next step will be formulation of this problem as a task with uncertainty parameters, [7].

\section{Acknowledgement}

The work has been supported by the grant project VEGA $1 / 1000 / 12$ and $1 / 1259 / 12$.

\section{References}

[1] SAGA, M., VASKO, M.: Stress Sensitivity Analysis of the Beam and Shell Finite Elements. Communications - Scientific Letters of the University of Zilina, vol. 11, No. 2, 2009, pp. 5-12.

[2] KOMPIS, V., TOMA, M., ZMINDAK, M., HANDRIK, M.: Use of Trefftz Functions in Non-linear, BEM/FEM, Computer and Structures, vol. 82, 2004, pp. 2351-2360.

[3] MELICHER, R., MESKO, J., NOVAK, P., ZMINDAK, M.: Residual Stress Simulation of Circumferential Welded Joints. Applied and Computational Mechanics, vol. 1, No. 2, 2010, pp. 541-544.

[4] SAGA, M., KOPAS, P., VASKO, M.: Some Computational Aspects of Vehicle Shell Frames Optimization Subjected to Fatigue Life. Communications - Scientific Letters of the University of Zilina, vol. 12, No. 4, 2010, pp. 73-79.

[5] Connecting Strain Gauges and Shunt Resistors to the NI 9237, http://digital.ni.com/public.nsf/allkb/892C84122A6501AE86257547007E5C53

[6] Strain Gauge Configuration Types, http://zone.ni.com/devzone/cda/tut/p/id/4172\#toc 9

[7] VASKO, M., SAGA, M.: Solution of Mechanical Systems with Uncertainty Parameters using IFEA, Communications - Scientific Letters of the University of Zilina, vol. 11, No. 2, 2009, pp. 19-27. 